Article

\title{
Tris(2,4,6-trimethoxyphenyl)phosphine (TTMPP): Efficient Catalysts for the Cyanosilylation and Cyanocarbonation of Aldehydes and Ketones
}

\author{
Satoru Matsukawa *, Izumi Sekine and Ayumi Iitsuka \\ Department of Science Education, Faculty of Education, Ibaraki University, Ibaraki, 310-8512 Japan
}

* Author to whom correspondence should be addressed; E-mail: smatsuka@mx.ibaraki.ac.jp;

Fax: +81292288234 .

Received: 6 August 2009; in revised form: 25 August 2009 / Accepted: 31 August 2009 /

Published: 2 September 2009

\begin{abstract}
A variety of aldehydes and ketones were transformed to their corresponding cyanohydrin silyl ethers in good to excellent yields in the presence of $1-5$ mol\% of tris(2,4,6-trimethoxyphenyl)phosphine (TTMPP). Cyanohydrin carbonates were also readily prepared using 5-10 mol\% of TTMPP as an organocatalyst.
\end{abstract}

Keywords: organocatalysis; cyanosilylaton; cyanohydrin carbonate; phosphines; cyanation

\section{Introduction}

The addition of trimethylsilyl cyanide (TMSCN) to carbonyl compounds is one of the most popular strategies to afford cyanohydrins, which can be conveniently converted into various important polyfunctionalized building blocks for the synthesis of many natural products and bioactive molecules, including $\alpha$-hydroxyl carbonyl compounds and $\beta$-amino alcohols [1-7]. Consequently, many catalytic systems, such as metal salts, organocatalysts, inorganic solid acids and bases, have been developed to enhance the efficiency of this transformation. Organophosphorous compounds have also been employed. Mukaiyama reported that $\mathrm{Bu}_{3} \mathrm{P}$ and $\mathrm{Ph}_{3} \mathrm{P}$ act as catalysts for the cyanosilylation with aldehydes [8]. Plumet [9,10] and Tian [11] independently reported that phosphonium salts-catalyzed cyanosilylation with aldehydes and ketones. Verkade's base (cycloazaphosphine) also acts as a good catalyst in this reaction [12]. In search of other useful organophosphorous catalysts, we have now 
examined the use of a highly basic phosphine, tris(2,4,6-trimethoxyphenyl)phosphine (TTMPP), as a catalyst.

TTMPP is known to be a highly basic phosphine owing to its extensive methoxy-substitution [13]. Based on this property, some unique catalytic reactions have been reported [14-19]. We have also reported that TTMPP acts as a good Lewis base catalyst in the reaction with silylated nucleophiles via O-Si and C-Si bond activation [20-25]. Herein we wish to report an efficient catalytic cyanosiyliation of various aldehydes and ketones using TTMPP as a catalyst.

\section{Results and Discussion}

Initially, the reactions of different aldehydes with trimethylsilyl cyanide in the presence of $1 \mathrm{~mol} \%$ of TTMPP in DMF at room temperature were examined. For both aromatics having an electrondonating or -withdrawing group and aliphatic aldehydes, the reaction proceeded quite smoothly and the desired products were obtained at high yield within $30 \mathrm{~min}$ (Table 1). The product was obtained in lower yield when other phosphines, such as $\mathrm{Bu}_{3} \mathrm{P}, \mathrm{Ph}_{3} \mathrm{P}$ and TMPP were used instead of TTMPP (Table 1, entries 1 vs. 10-12). The reaction also smoothly proceeded in THF. However, the reactions performed in MeCN and toluene were inferior when compared to those in DMF and THF.

Table 1. Cyanosilylation of various aldehydes. ${ }^{[a]}$

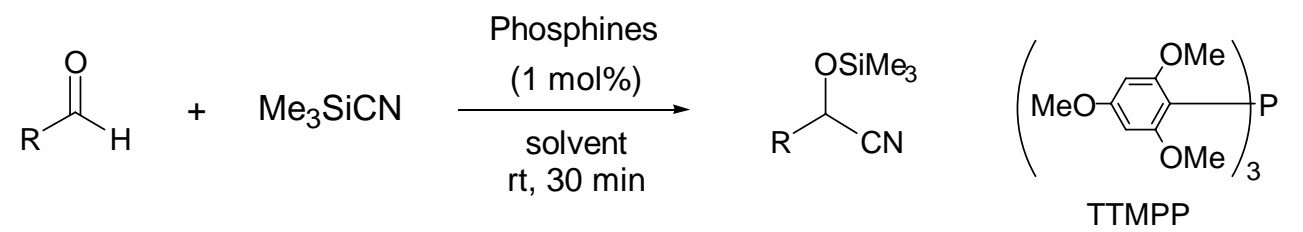

\begin{tabular}{|c|c|c|c|c|}
\hline Entry & Phosphines & Aldehyde & solvent & Yield (\%) \\
\hline 1 & ТTMРP & $\mathrm{C}_{6} \mathrm{H}_{5} \mathrm{CHO}$ & DMF & 98 \\
\hline 2 & & $4-\mathrm{CH}_{3} \mathrm{OC}_{6} \mathrm{H}_{4} \mathrm{CHO}$ & & 99 \\
\hline 3 & & $4-\mathrm{ClC}_{6} \mathrm{H}_{4} \mathrm{CHO}$ & & 95 \\
\hline 4 & & $4-\mathrm{NO}_{2} \mathrm{C}_{6} \mathrm{H}_{4} \mathrm{CHO}$ & & 98 \\
\hline 5 & & $\alpha$-Naphthaldehyde & & 92 \\
\hline 6 & & $\beta$-Naphthaldehyde & & 90 \\
\hline 7 & & $\mathrm{C}_{8} \mathrm{H}_{17} \mathrm{CHO}$ & & 95 \\
\hline 8 & & $\mathrm{C}_{6} \mathrm{H}_{5} \mathrm{CH}_{2} \mathrm{CH}_{2} \mathrm{CHO}$ & & 92 \\
\hline 9 & & cyclo- $\mathrm{C}_{6} \mathrm{H}_{11} \mathrm{CHO}$ & & 93 \\
\hline 10 & $\mathrm{TMPP}^{[\mathrm{b}]}$ & $\mathrm{C}_{6} \mathrm{H}_{5} \mathrm{CHO}$ & & 45 \\
\hline 11 & $\mathrm{Ph}_{3} \mathrm{P}$ & & & 30 \\
\hline 12 & ${ }^{n} \mathrm{Bu}_{3} \mathrm{P}$ & & & 68 \\
\hline 13 & ТTMPР & & THF & 95 \\
\hline 14 & & & $\mathrm{CH}_{3} \mathrm{CN}$ & 55 \\
\hline 15 & & & toluene & 30 \\
\hline
\end{tabular}

[a] Reactions were carried out on a 0.5 mmol scale with 1.2 equiv of TMSCN.

[b] Tris(4-methoxyphenyl)phosphine. 
Table 2. TTMPP-Catalyzed cyanosilylation of various ketones. ${ }^{\text {[a] }}$

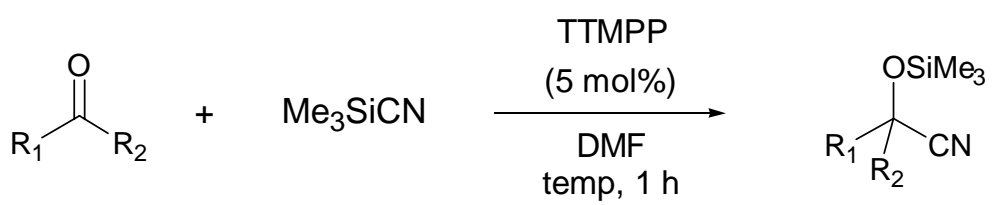

\begin{tabular}{|c|c|c|c|}
\hline Entry & Ketones (3) & Temp $\left({ }^{\circ} \mathrm{C}\right)$ & Yield (\%) \\
\hline 1 & & r.t. & 97 \\
\hline $2^{[b],[c]}$ & & & 99 \\
\hline 3 & & & 95 \\
\hline 4 & $\mathrm{C}_{6} \mathrm{r}$ & & 93 \\
\hline 5 & & & 98 \\
\hline 6 & 0,4 & & 90 \\
\hline 7 & & & 93 \\
\hline 8 & & & 94 \\
\hline 9 & & & 76 \\
\hline $10^{[\mathrm{d}]}$ & & r.t. & trace \\
\hline 11 & & $50^{\circ} \mathrm{C}$ & 97 \\
\hline 12 & & & 96 \\
\hline 13 & $4-\mathrm{CH}_{3} \mathrm{OC}_{6}$ & & 95 \\
\hline 14 & $u_{6}$ & & 95 \\
\hline
\end{tabular}

Next, we investigated the scope of this TTMPP-catalyzed reaction of ketones (Table 2). In the case of aliphatic ketones, the reaction proceeded smoothly in the presence of $5 \mathrm{~mol} \%$ of TTMPP in DMF at room temperature. Good results were obtained for both acyclic and cyclic ketones. This reaction also proceeded smoothly when 1 mol\% of TTMPP was used. Only 1,2-addition products were observed for unsaturated ketones. On the other hand, for the typical aromatic ketone acetophenone, only a trace amount of the product was obtained at room temperature even after $24 \mathrm{~h}$. Then, the reaction was carried out at the elevated temperature. The desired product was obtained in $95 \%$ yield at $50{ }^{\circ} \mathrm{C}$ in 
DMF within $1 \mathrm{~h}$. Under the same conditions, a variety of aromatic ketones were transformed to their corresponding cyanohydrin silyl ethers in high yield.

Cyanocarbonation [26-33] of aldehydes and ketones with cyanoformate was also examined (Table 3). Cyanohydrin carbonates are configurationally stable and significantly less prone to hydrolysis than cyanohydrin trimethylsilyl ethers. We examined the scope of this TTMPP-catalyzed reaction of aldehydes and ketones using methyl cyanoformate. Good results were obtained for both aromatics having an electron-donating or -withdrawing group and aliphatic aldehydes in the presence of $5 \mathrm{~mol} \%$ of TTMPP in THF at room temperature. The reaction also proceeded smoothly with various aliphatic ketones in the presence of 10 mol\% TTMPP, but was unsuccessful with aromatic ketones under these conditions.

Table 3. TTMPP-Catalyzed cyanocarbonation of aldehydes and ketone. ${ }^{[a]}$

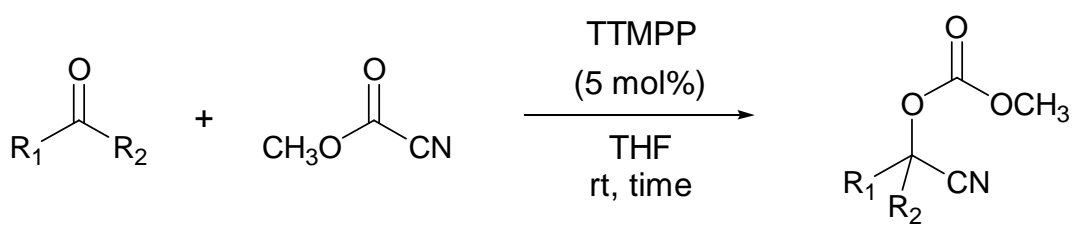

\begin{tabular}{cccc}
\hline Entry & Carbonyl Compound (3) & Time (h) & Yield (\%) \\
\hline 1 & $\mathrm{C}_{6} \mathrm{H}_{5} \mathrm{CHO}$ & $1 \mathrm{~h}$ & 98 \\
2 & $4-\mathrm{CH}_{3} \mathrm{OC}_{6} \mathrm{H}_{4} \mathrm{CHO}$ & $4 \mathrm{~h}$ & 85 \\
3 & $4-\mathrm{ClC}_{6} \mathrm{H}_{4} \mathrm{CHO}$ & & 95 \\
4 & $4-\mathrm{BrC}_{6} \mathrm{H}_{4} \mathrm{CHO}$ & & 98 \\
5 & $4-\mathrm{NO}_{2} \mathrm{C}_{6} \mathrm{H}_{4} \mathrm{CHO}$ & & 88 \\
6 & $\alpha-\mathrm{Naphthaldehyde}_{7}$ & $1 \mathrm{~h}$ & 98 \\
7 & $\beta-\mathrm{Naphthaldehyde}_{8}$ & & 85 \\
9 & $\mathrm{C}_{8} \mathrm{H}_{17} \mathrm{CHO}$ & $4 \mathrm{~h}$ & 87 \\
10 & $\mathrm{C}_{6} \mathrm{H}_{5} \mathrm{CH}_{2} \mathrm{CH}_{2} \mathrm{CHO}$ & & 92 \\
$11^{[\mathrm{b}]}$ & $c y c l o-\mathrm{C}_{6} \mathrm{H}_{11} \mathrm{CHO}$ & & 88 \\
$12^{[\mathrm{b}]}$ & $\mathrm{C}_{6} \mathrm{H}_{13} \mathrm{COCH}_{3}$ & $20 \mathrm{~h}$ & 75 \\
$13^{[\mathrm{b}]}$ & $\mathrm{C}_{6} \mathrm{H}_{5} \mathrm{CH}_{2} \mathrm{CH}_{2} \mathrm{COCH}$ & & 85 \\
$14^{[\mathrm{b}],[\mathrm{cc}]}$ & $\mathrm{C}_{6} \mathrm{H}_{5} \mathrm{COCH}_{3}$ & $24 \mathrm{~h}$ & 5 \\
\hline
\end{tabular}

[a] Reactions were carried out on a 0.5 mmol scale with 1.5 equiv of methyl cyanoformate; ${ }^{[\mathrm{b}]} 10 \mathrm{~mol} \%$ of TTMPP was used; ${ }^{[c]}$ At $50{ }^{\circ} \mathrm{C}$.

\section{Experimental}

\section{General}

All reactions were performed under an argon atmosphere using oven-dried glassware. Flash column chromatography was performed using silica gel Wakogel C-200. Preparative thin-layer chromatography was carried out on silica gel Wakogel B-5F. Dehydrate DMF, THF, toluene and 
$\mathrm{CH}_{3} \mathrm{CN}$ were purchased from Wako Chemical. Other commercially available reagents were used as received without further purification. ${ }^{1} \mathrm{H}$ NMR and ${ }^{13} \mathrm{C}$ NMR spectra were recorded on a JEOL JMNGS400 spectrometer (399.65 $\mathrm{MHz}$ for ${ }^{1} \mathrm{H}$ and $100.40 \mathrm{MHz}$ for ${ }^{13} \mathrm{C}$ ).

General Procedure for the TTMPP-Catalyzed Cyanosilylation of Aldehydes and Ketones

To a solution of TTMPP $(0.05 \mathrm{mmol})$ in DMF $(1 \mathrm{~mL})$ was added aldehyde or ketone $(0.5 \mathrm{mmol})$ and trimethylsilyl cyanide $(0.60 \mathrm{mmol})$ at room temperature. After stirring for $30 \mathrm{~min}$, the resultant mixture was quenched with water. The mixture was extracted with EtOAc and organic layer was washed with brine and dried over anhydrous $\mathrm{Na}_{2} \mathrm{SO}_{4}$, and evaporated. The crude mixture was purified by column chromatography on silica gel (EtOAc-hexane $=1: 10$ ) to give the corresponding product. The products are all known compounds identified by their spectroscopic data and comparison with literature values [8-12,34]. The purity of the product was confirmed by ${ }^{1} \mathrm{H}$ NMR analysis.

General Procedure for the TTMPP-Catalyzed Cyanocarbonation of Aldehydes

To a solution of TTMPP $(0.05 \mathrm{mmol})$ in THF $(1 \mathrm{~mL})$ was added aldehyde $(0.5 \mathrm{mmol})$ and methyl cyanoformate $(0.75 \mathrm{mmol})$ at room temperature. After stirring for $30 \mathrm{~min}$, the resultant mixture was quenched with water. The mixture was extracted with $\mathrm{Et}_{2} \mathrm{O}$ and organic layer was washed with brine and dried over anhydrous $\mathrm{Na}_{2} \mathrm{SO}_{4}$, and evaporated. The crude mixture was purified by column chromatography on silica gel (EtOAc-hexane $=1: 3$ ) to give the corresponding product. The products are all known compounds identified by their spectroscopic data and comparison with literature values [27-33]. The purity of the product was confirmed by ${ }^{1} \mathrm{H}$ NMR analysis.

$\alpha$-(Trimethylsilyloxy)phenylacetonitrile: ${ }^{1} \mathrm{H}-\mathrm{NMR}\left(400 \mathrm{MHz}, \mathrm{CDCl}_{3}\right) \delta 0.21$ (s, 9H), 5.45 (s, 1H), 7.35 -7.50 (m, 5H); ${ }^{13} \mathrm{C}$ NMR (100 MHz, $\left.\mathrm{CDCl}_{3}\right) \delta-0.3,63.4,119.1,126.0,128.4,129.0,136.0$.

2-Trimethylsilyloxy-2-phenylpropanenitrile: ${ }^{1} \mathrm{H}-\mathrm{NMR}\left(400 \mathrm{MHz}, \mathrm{CDCl}_{3}\right) \delta 0.17(\mathrm{~s}, 9 \mathrm{H}), 1.85$ (s, 3H), 7.35 - 7.56 (m, 5H); ${ }^{13} \mathrm{C}$ NMR $\left(100 \mathrm{MHz}, \mathrm{CDCl}_{3}\right) \delta 1.0,33.5,71.5,121.3,124.8,128.4,141.9$.

$\alpha$-(Methoxycarboxy)phenylacetonitrile: ${ }^{1} \mathrm{H}-\mathrm{NMR}\left(400 \mathrm{MHz}, \mathrm{CDCl}_{3}\right) \delta 3.87$ (s, 3H), 6.28 (s, 1H), 7.39 - 7.55 (m, 5H); ${ }^{13} \mathrm{C}$ NMR (100 MHz, $\left.\mathrm{CDCl}_{3}\right) \delta$ 55.9, 66.6, 115.6, 127.8, 129.1, 130.6, 131.1, 153.9.

\section{Conclusions}

In conclusion, we demonstrated that TTMPP catalyzes cyanosilylation reactions using TMSCN. TTMPP effectively activated the C-Si bond of TMSCN, and the reaction proceeded smoothly to afford the corresponding products. This reaction can be applied to wide variety of aldehydes and ketones. Cyanohydrin carbonates could also be readily prepared with methyl cyanoformate using 5-10 mol\% of TTMPP as catalyst. 


\section{References}

1. Evans, D.A.; Truesdale, L.K. Carbonyl insertion reactions of silicon pseudohalides: catalysis. Tetrahedron Lett. 1973, 4929-4932.

2. Evans, D.A.; Carroll, G.L.; Truesdale, L.K. Synthetic applications of trimethylsilyl cyanide. An efficient synthesis of aminomethyl alcohols. J. Org. Chem. 1974, 39, 914-917.

3. North, M. Catalytic, asymmetric cyanohydrin formation. Synlett, 1993, 807-820.

4. Gregory, J.H. Cyanohydrins in nature and the laboratory: Biology, preparations, and synthetic applications. Chem. Rev. 1999, 99, 3649-3682.

5. North, M. Synthesis and applications of non-racemic cyanohydrins. Tetrahedron: Asymmetry 2003, 14, 147-176.

6. Brunel, J.-M.; Holmes, I.P. Chemically catalyzed asymmetric cyanohydrin syntheses. Angew. Chem. Int. Ed. 2004, 43, 2752-2778.

7. Khan, N.H.; Kureshy, R.I.; Abdi, S.H.R.; Agrawal, S.; Jasra, R. Metal catalyzed asymmetric cyanation reactions. Cood. Chem. Rev. 2008, 252, 593-623.

8. Kobayashi, S.; Tsuchiya, Y.; Mukaiyama, T. A facile sythesis of cyanohydrin trimethylsilyl ethers by the addition reaction of trimethylsilyl cyanide with aldehydes under basic condition. Chem. Lett. 1991, 537-540.

9. Córdoba, R.; Plumet, J. Methyltriphenylphosphonium iodide catalyzes the addition of trimethylsilyl cyanide to aldehydes. Tetrahedron Lett. 2003, 44, 6157-6159.

10. Amurrio, I.; Córdoba, R.; Csákÿ, A.G.; Plumet, J. Tetrabutylammonium cyanide catalyzes the addition of TMSCN to aldehydes and ketones. Tetrahedron 2004, 60, 10521-10524.

11. Wang, X.; Tian, S.-K. Catalytic cyanosilylation of ketones with simple phosphonium salt. Tetrahedron Lett. 2007, 48, 6010-6013.

12. Fetterly, B.; Verkade, J.G. $\mathrm{P}\left(\mathrm{RNCH}_{2} \mathrm{CH}_{2}\right) \mathrm{N}$ : Efficient catalysis for the cyanosilylation of aldehydes and ketones. Tetrahedron Lett. 2005, 46, 8061-8066.

13. Wada, M.; Higashizaki, S. A highly basic triphenylphosphine, [2,4,6-(MeO) $\left.{ }_{3} \mathrm{C}_{6} \mathrm{H}_{2}\right]_{3} \mathrm{P}$. J. Chem. Soc. Chem. Commun. 1984, 482-483.

14. Yoshimoto, K.; Kawabata, H.; Nakamichi, N.; Hayashi, M. Tris(2,4,6-trimethoxyphenyl)phosphine (TTMPP): A novel catalyst for selective deacetylation. Chem. Lett. 2001, 30, 934-935.

15. Kawabata, H.; Hayashi, M. Lewis base-catalyzed transformation of $\alpha, \beta$-unsaturated aldehydes to saturated carboxylic acids, esters, and amides. Tetrahedron Lett. 2002, 43, 5645-5647.

16. Weeden, J.A.; Chisfolm, J.D. Phosphine-catalyzed nitroaldol reactions. Tetrahedron Lett. 2006, 47, 9313-9316.

17. Hirata, N.; Hayashi, M. Nitroaldol reaction catalyzed by tris(2,4,6-trimethoxyphenyl)phosphine (TTMPP). Synth. Commun. 2007, 37, 1653-1657.

18. Chuprakov, S.; Malyshev, D.A.; Trofimov, A.; Gevorgyan, V. Sila Morita-Baylis-Hillman reaction of cyclopropenes. J. Am. Chem. Soc. 2007, 129, 14868-14869.

19. Trofimov, A.; Gevorgyan, V. Sila-Morita-Baylis-Hillman reaction of arylvinyl ketones: overcoming the dimerization problem. Org. Lett. 2009, 11, 253-255. 
20. Matsukawa, S.; Okano, N.; Imamoto, T. Phosphine catalyzed aldol reaction between ketene silyl acetals and aldehydes: nucleophilic $\mathrm{O}-\mathrm{Si}$ and $\mathrm{C}-\mathrm{Si}$ bond cleavage by phosphines. Tetrahedron Lett. 2000, 41, 103-107.

21. Matsukawa, S.; Obu, K. TTMPP catalyzed one-pot silyl ketene acetal-imine condensation route to $\beta$-lactams. Chem. Lett. 2004, 33, 1626-1627.

22. Matsukawa, S.; Kitazaki, E. Catalytic cyanomethylation of carbonyl compounds and imines with highly basic phosphine Tetrahedron Lett. 2008, 49, 2982-2984.

23. Matsukawa, S.; Saijo, M. TTMPP-catalyzed trifluoromethylation of carbonyl compounds and imines with trifluoromethylsilane. Tetrahedron Lett. 2008, 49, 4855-4857.

24. Matsukawa, S.; Sekine, I. TTMPP-catalyzed addition of alkynes using trimethylsilylacetylenes. Synth. Commun. 2009, 39, 1718-1721.

25. Matsukawa, S.; Tsukamoto, K. TTMPP: An efficient organocatalyst in the ring-opening of aziridines with silylated nucleophiles. Org. Biomol. Chem. 2009, 7, 3792-3796.

26. Belokon', Y.N.: Clegg, W.; Harrington, R.W.; Ishibashi, E.; Nomura, H.; North, M. Enantioselective and Diastereoselective Syntheses of Cyanohydrin Carbonates. Tetrahedron 2007, 63, 9724-9740.

27. Tian, S.-K.; Deng, Li. Enantioselective cyanocarbonation of ketones with chiral base. Tetrahedron 2006, 62, 11320-11330.

28. Scholl, M.; Lim, C.-K.; Fu, G.C. Convenient and efficient conversion of aldehydes to acylated cyanohydrins using tributyltin cyanide as a catalyst. J. Org. Chem. 1995, 60, 6229-6231.

29. Okimoto, M.; Chiba, T. A convenient and improved method for the preparation of cyanohydrin esters from acyl cyanides and aldehydes. Synthesis 1996, 1188-1190.

30. Tian, S.-K.; Deng, Li. A highly enantioselective chiral Lewis base-catalyzed asymmetric cyanation of ketones. J. Am. Chem. Soc. 2001, 123, 6195-6196.

31. Tian, J.; Yamagiwa, N.; Matsunaga, S.; Shibasaki, M. An asymmetric cyanation reaction and sequential asymmetric cyanation-nitroaldol reaction using a [YLii $\{$ tris(binaphthoxide)\}] single catalyst component: Catalyst tuning with achiral additives. Angew. Chem. Int. Ed. 2002, 41, 3636-3638.

32. Iwanami, K.; Hinakubo, Y.; Oriyama, T. Catalyst-free DMSO-promoted synthesis of cyanohydrin carbonates from aldehydes. Tetrahedron Lett. 2005, 46, 5881-5883.

33. Chinchilla, R.; Nájera, R.; Ortega, F.J. Enantioselective cyanoformylation of aldehydes using a recyclable dimeric cinchonidine ammonium salt as an organocatalyst. Tetrahedron: Asymmetry 2008, 19, 265-268.

34. Prakash, G.K.S.; Vaghoo, H.; Panja, C.; Surampudi, V.; Kultyshev, R.; Mathew, T.; Olah, G. A. Effect of carbonates/phosphates as nucleophilic catalysts in dimethylformamide for efficient cyanosilylation of aldehydes and ketones. Proc. Natl. Acad. Sci. USA 2007, 104, 3026-3030.

Sample Availability: Samples of the compounds of interest are available from the authors.

(C) 2009 by the authors; licensee Molecular Diversity Preservation International, Basel, Switzerland. This article is an open-access article distributed under the terms and conditions of the Creative Commons Attribution license (http://creativecommons.org/licenses/by/3.0/). 